\title{
Sea State Primitive Object Creation from SAR Data
}

\author{
Konstantinos Topouzelis, Dimitra Kitsiou \\ Department of Marine Sciences, School of the Environment, University of the Aegean, Mytilene, Greece \\ Email: topouzelis@marine.aegean.gr
}

Received 17 October 2014; revised 12 November 2014; accepted 4 December 2014

Copyright (C) 2014 by authors and Scientific Research Publishing Inc.

This work is licensed under the Creative Commons Attribution International License (CC BY). http://creativecommons.org/licenses/by/4.0/

(c) (i) Open Access

\section{Abstract}

Wide swath Synthetic Aperture Radar (SAR) images acquired over sea areas contain a variety of information regarding small scale and mesoscale phenomena in the ocean and marine boundary layer e.g. spills, slicks, surface or internal waves, eddies, oceanic fronts. One of most challenging processing step is to create image objects describing these phenomena on SAR images. The most significant problem in the wide swath images is the backscattering trend at the range direction, which results a progressive brightness reduction over images from near to far range. This reduction affects the detection and classification of sea surface features on wide swath SAR images and a normalization step is needed in a certain incidence angle for compensating the brightness reduction. The aim of the present paper is to investigate the result of image normalization to a set of Wide Swath Mode SAR images. Dark areas were initially detected in SAR images using thresholds, adapted or not. Afterwards, SAR images were normalized and a global threshold was calculated for each image. Images were segmented and objects were created for each dark area. The results were compared to a reference dataset created from theoretical modeled values and extracted in a GIS environment. Results clearly indicate that overall accuracy of the detected dark areas has been increased after normalization. On the contrary, local thresholds were insufficient in producing acceptable results. The proposed normalization can be used as a pre-processing step in image classification.

\section{Keywords}

Synthetic Aperure Radar, Ocean, Normalization, Object Creation

\section{Introduction}

Dark formation detection in Synthetic Aperture Radar (SAR) imagery is considered a fundamental procedure for 
oceanographic studies by satellite means; for example, in oil spill detection systems dark detection represents the first important step. Once dark formations are detected, classification methods are applied to characterize them as oil spills or look-alikes. If dark formations are not detected in this step they will be never classified.

Dark formations can be located manually by cropping a broader area containing them, or an image window with fixed size can be used, in which threshold algorithms — adapted or not—can be applied. Threshold represents an appropriate value that determines which pixels will be considered as dark formations and which as "clean" sea-background. Simple thresholds have one value for the whole image e.g. the half of the average Normalized Radar Cross Section (NRCS) of the image [1], or the NRSC minus the standard deviation [2]. In adaptive algorithms threshold is calculated locally, mainly in areas covered by a moving window. Researchers [3] have used an adaptive threshold which was calculated using the mean value of a moving window in different scales of the image. In [4] the threshold is fully adaptive to local contrast and brightness of large image segments, therefore the image window does not have a fixed size but it varies according to brightness and contrast values of large areas in the image. In [5] an edge detection technique was used based on image histograms which were derived from areas with potential dark formations.

All the above studies used statistical based techniques to locate dark formations. A different approach is given by [6] were the use of wavelets for oil spill detection was described. This study was performed for ocean feature detection on SAR data including oil spills. In later studies [7] wavelets were used specific for the oil spill detection problem. Moreover, in [8], dark formations were detected using a fractal dimension estimation, where a multi resolution algorithm based on fractal geometry for texture analysis was applied. Later [9], presented a method for modification of the formula of the fractal box counting dimension, a more sophisticated technique, based on texture analysis, where several textures (i.e. entropy, homogeneity, contrast, energy and correlation) were examined to detect dark formations. Finally, [10] proposed a neural network approach to detect dark formations using high resolution SAR images.

The most common satellite mode for oceanographic purposes are the SAR's wide swath mode in which many dark areas can be detected [11]. SAR imagery is applicable to many oceanographic phenomena: fronts, waves, eddies, winds, storms, oil spills, algae blooms, currents, and boundary layer rolls are some examples of the observation capabilities of SAR sensors. SARs' ability to retrieve data in all weather conditions, independently of the availability of sunlight and, with the help of processing methods, to produce high resolution images of the ocean surface, is extremely important for oceanographic studies. SAR imagery quality is dependent on the mode of acquisition and raw data processing. ENVISAT's Wide Swath Mode (WSM) with 150 m resolution, a swath width of $405 \mathrm{~km}$ and two possible mutually exclusive polarizations (VV or $\mathrm{HH}$ ) is ideal for oceanographic studies. In addition, the existence of wide swath sensors in past (ENVISAT ASAR, RADARSAT-1), current (RAD ARSAT-2, COSMOS-SkyMED, TerraSAR-X, RISAT-1, ALOS/PALSAR, Sentinel-1A) or future (Sentinel-1B and PAZ) systems leads to a systematic use of medium-resolution (40 - $100 \mathrm{~m})$ data for the mapping of oceanographic phenomena at a large scale.

The main issue related to wide swath SAR images is the progressive decrease of backscatter energy from near to far range. Variation of Normalized Radar Cross-Section (NRCS) values derived from SAR images depends on the content of the observed scene as well as the sea and atmospheric conditions at the time of observation. The backscattering trend at the range direction resulted by the progressive brightness reduction over images from near to far range, affected the detection and classification of sea surface features on wide swath SAR images. In the present study the original SAR images where normalized using a theoretical backscattering derivation based on image geometry. The normalization step was applied in a certain incidence angle for compensating the brightness reduction. The aim of the present paper is to investigate the result of image normalization using the dark areas contained in SAR imagery under a Geographic Object-Based Image Analysis (GEOBIA) environment. Normalization can help operators to visualize the image in a more usable way in order to identify ocean phenomena through visual interpretation or can be used as a pre-processing step for meso-scale oceanographic phenomena detection and classification (e.g. oil spills, eddies, currents, or fronts). Last but not least, normalization can be used for inter-comparison of many SAR images or data from the same or a different sensor regardless of the sea state and environmental conditions.

\section{Materials and Method}

\subsection{Study Area and Dataset}

The study area was the central part of the Aegean Sea, Greece (Figure 1) where numerous oceanographic phe- 


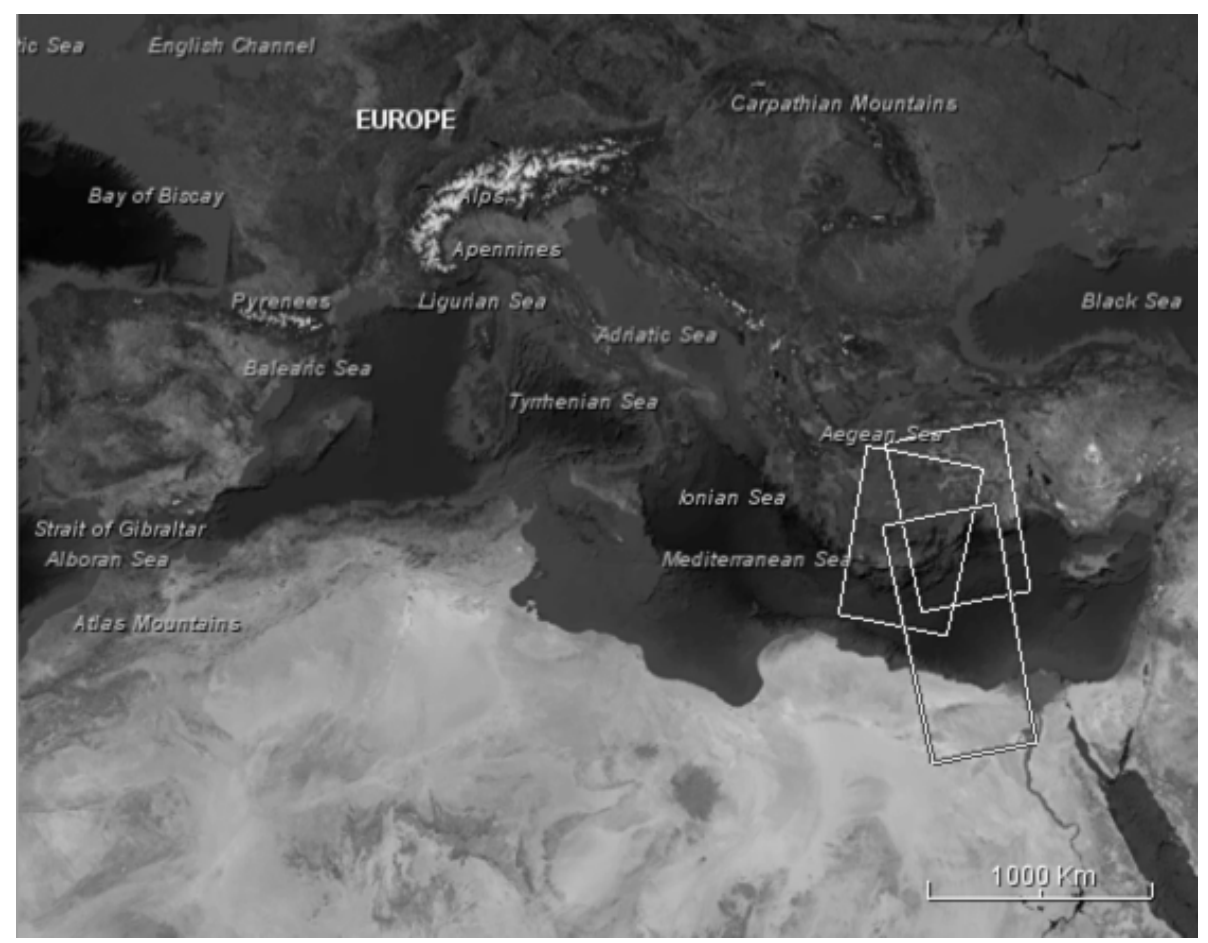

Figure 1. Area of study and example of three SAR images covering the study area.

nomena can be detected in a satellite image. The Aegean Sea is located between the southern Balkan and Anatolian peninsulas between the main lands of Greece and Turkey. In the north, it is connected to the Marmara Sea and Black Sea by the Dardanelles and Bosporus and in the South with Eastern Mediterranean Sea. Two of the biggest islands, Crete and Rhodes, are bound on its southern periphery. The Aegean Sea has an average depth of about $350 \mathrm{~m}$ and a maximum depth of $3543 \mathrm{~m}$ east of Crete. It is a complex Archipelago with high irregular coastline which combines semi-isolated deep basins and shallow bays. It shares many aspects with other marginal seas such as Adriatic, and the obtained surface circulation is a combination of wind-driven and thermohaline driven flows [12]. Aegean Sea is characterized from special dynamic conditions, because of its hydro-morphological characteristics, the irregular and complicated topography regarding the presence of many small islands at the most of the area and the hydro-physical conditions as a transiting region of different water masses. In addition, Aegean Sea is the only connection between Mediterranean and Black Sea. The general circulation of the Aegean Sea is characterized by a multiple scale pattern that includes a basin scale cyclonic flow, sub-basin scale recurrent gyres and a number of transient eddies [13]. The northern part of the basin is dominated by the presence of the low-salinity Black Sea Waters (BSW) that enters the Aegean through the straits of Dardanelles and influences its hydrology and circulation. The presence of such different water-masses creates strong temperature and salinity contrasts between the N-NW cold and fresh areas and the S-SE warm and saline parts of the North Aegean basin, which can lead to high presence of frontal areas to the region and formation of a complex eddy field.

\subsection{Data Set}

In this study Advanced Synthetic Aperture Radar (ASAR) images were used, acquired from ENVISAT satellite. ASAR is an imaging microwave radar operated at C-band operating in several modes i.e. alternative polarization, image, wave, global and wide swath. ASAR Wide Swath Mode (WSM) images could be acquired in HH or VV polarisation with ground resolution of $150 \times 150 \mathrm{~m}$ covering a swath of $405 \mathrm{~km}$. The scattering properties of the ocean depend on the polarization and VV is proposed as being more appropriate for several oceanographic phenomena like oil spills [14]. The ASAR WSM dataset is generated from Level 0 data collected in the Scan SAR mode. This type of product includes slant range to ground range corrections and it covers a continuous area along the imaging swath. The incident angle of the images was approximately $15^{\circ}$ to $45^{\circ}$ and the image cover 
was approximately $400 \mathrm{~km}$ in the slant direction and $1000 \mathrm{~km}$ in the azimuth direction [15].

In total, 10 ASAR images were used in WSM and VV polarization. The dataset was acquired for the year 2011. Images were captured under different wind conditions. Several oceanographic phenomena were present in each image and all images contained dark areas to detect. Progressive reduction of backscattering signal has obviously prohibited the image analysis in the far range.

\subsection{Methodology}

Dark objects were detected in SAR imagery through a methodological framework as described in Figure 2. Dark areas were initially detected in SAR images using thresholds, adapted or not. Afterwards, SAR images were normalized and a global threshold was calculated for each image. Images were segmented and objects were created for each dark area. The results were compared to a reference dataset created from theoretical modelled values and extracted in a GIS environment.

A pre-processing step was required for converting image data in a certain format in order to proceed to image classification. This step was essential for the stability of the classification and the accuracy of the method. Preprocessing included calibration, filtering, land masking and geotiff export.

The objective of radar calibration is to provide imagery in which the pixel values can be directly related to the radar backscatter of the scene [16]. While non-calibrated SAR imagery is sufficient for qualitative use, calibrated SAR images are essential for quantitative use of SAR data. During the calibration process, data is transformed from amplitude to $\sigma_{0}$ (or Sigma-0, sigma nought, or Normalized Radar Cross Section-NRCS) values. NRCS values describe the (mean) reflectivity of a patch of distributed scatterers per unit area of a horizontal surface [17]. To calibrate images, i.e. to convert amplitude of backscatter A given in WSM ASAR image data to Normalized Radar Cross Section (NRCS), the following formula is used [16]:

$$
\operatorname{NRCS}_{i, j}=\frac{\mathrm{DN}_{i, j}^{2}}{K} \sin \left(\theta_{i, j}\right)
$$

where $K$ is the absolute calibration constant, $\mathrm{DN}_{i, j}^{2}$ is the pixel intensity value at image line " $i$ " and column " $j$ ", and $\theta$ is the incidence angle.

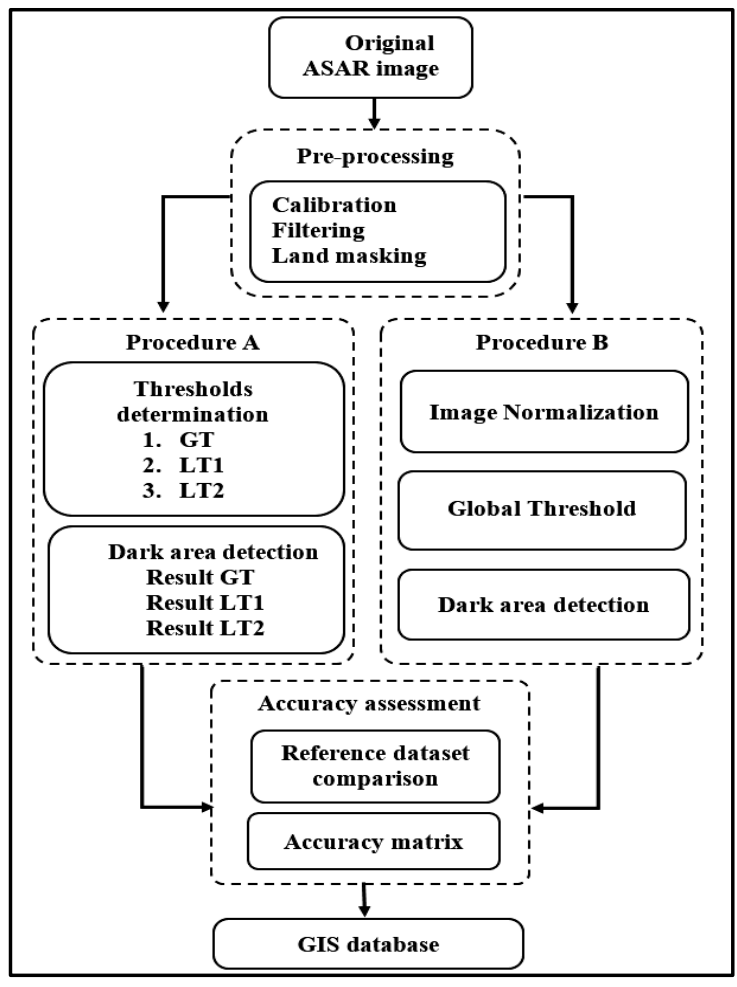

Figure 2. Methodological framework. 
Filtering was applied to calibrated images in order to reduce their speckle and to improve the image segmentation. It was performed by an Enhanced Lee filter with size $3 \times 3$ pixels. Land masking aimed to reduce the image size excluding the land from the processing chain. It was performed using the Global Self-Consistent Hierarchical High-Resolution Shoreline (GSHHS) provided by NOAA [18].

After pre-processing two parallel procedures for detecting dark areas were executed; one using the SAR images without any further processing and one after normalizing them. In the first procedure dark areas were initially detected using a global threshold. Global threshold (GT) was calculated by subtracting the standard deviation of the image values from the Mean image value according to Equation (2). However, very low accuracy results were expected by GT because of the obvious progressive reduction of the NRSC values in the original images. For eliminating that problem two local adapted thresholds was calculated according to Equations (3), (4) respectively. Local thresholds were calculated using local statistical values of mean and standard deviation from sub areas (windows) of the images. From the three thresholds and for each image, objects were created describing the low backscattering signal.

$$
\begin{gathered}
\text { Global Threshold (GT) : } \text { Mean }_{\text {image }}-\operatorname{St} \operatorname{Dev}_{\text {image }} \\
\text { Local Threshold 1 (LT1): Mean } \\
\text { pixel }
\end{gathered}
$$

The second parallel procedure was to normalize the images and examine the efficiency of the dark areas detection using a global threshold. Image normalization is related to the correction of the progressive decrease of backscatter energy from near to far range in wide swath SAR images. A theoretical backscattering shape function derivation was used. It is a theoretical backscattering profile in range direction for the ENVISAT's ASAR C radar band. It uses only information from the image geometry: its incident angle $\theta$ and the theoretical NRCS value at wind speed of $2.5-3 \mathrm{~m} / \mathrm{sec}$. For C band SAR sensors, NRCS at incidence angles $16^{\circ}-45^{\circ}$ follow a linear distribution among $2.5-(-20) \mathrm{dB}$ [17] [19]. Therefore the theoretical NRCS $\theta$ (or $\sigma_{\theta}^{0}$ ) values for $\theta 16^{\circ}$ $45^{\circ}$ can be described by (5).

$$
\sigma_{\theta}^{0}=-0.776 \theta+14.914
$$

For reference angle $\left(\theta=30^{\circ}\right)$ the symmetric function $\left(\sigma_{\theta}^{0}\right)^{-1}$ of Equation (5) to angle of reference is:

$$
\left(\sigma_{\theta\left(30^{\circ}\right)}^{0}\right)^{-1}=0.776 \theta-31.638
$$

This function is averaged with the original SAR images producing the normalized result. For the produced results dark areas were detected using the global threshold as described previously according to Equation (2).

Consequently, objects containing the dark areas were created by both parallel procedures. Next stage was the accuracy assessment which was achieved using a reference dataset. Reference dataset (accuracy assessment masks) was created using the theoretical values of $(-30)-(-13.5) \mathrm{dB}$, which represent $1.5-2 \mathrm{~m} / \mathrm{sec}$ wind speed i.e. practical dark areas in SAR images [17]. Comparison for the dark areas detected without and after normalization was carried out using accuracy assessment masks. Accuracy matrices [20] were produced for two class problem i.e. dark areas and sea background. An example of original image, its normalization and the produced mask is given in Figure 3. It is clearly illustrated the progressive reduction of the normalized radar backscatter before normalization (from near to far range) and its absence after normalization. Also an example of the produced mask is given according to the theoretical backscattering values of a certain angle of incidence and wind speed. In addition, an example of the image histograms before and after normalization is given in Figure 4. Before normalization, the image contained backscatter values among $(-30)-(2.5 \mathrm{~dB})$ i.e. range of $32 \mathrm{~dB}$ while after normalization the available range shrink to $(-20)-(-8.5 \mathrm{~dB})$ i.e. range of $11.5 \mathrm{~dB}$. Comparison of the results was carried out within object-based image analysis environment and the objects with the higher dark area accuracy were extracted in a GIS environment. A spatial database was created where the dark areas present in the study area were stored as polygons.

\section{Results and Discussion}

Ten ENVISAT's ASAR images were used for detecting existed dark formations in the study area. Different wind 


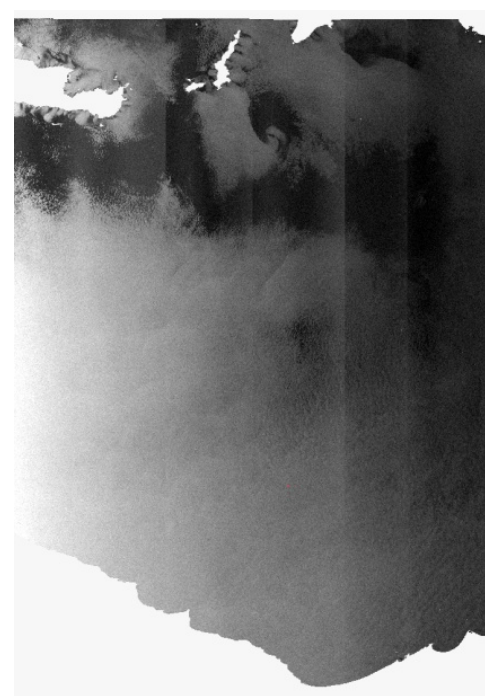

(a)

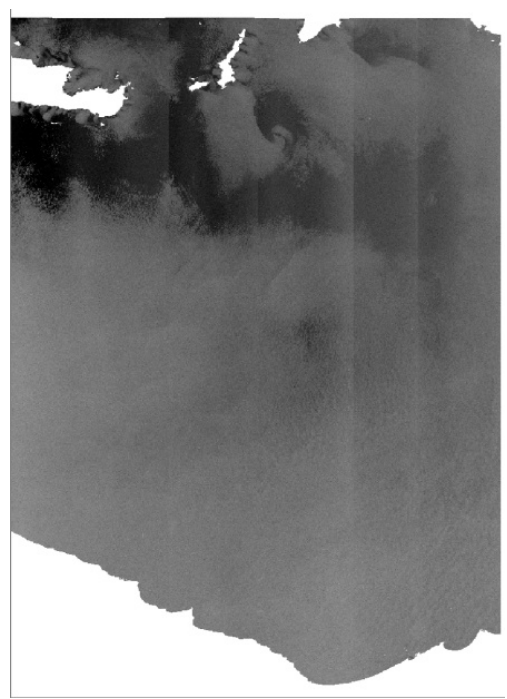

(b)

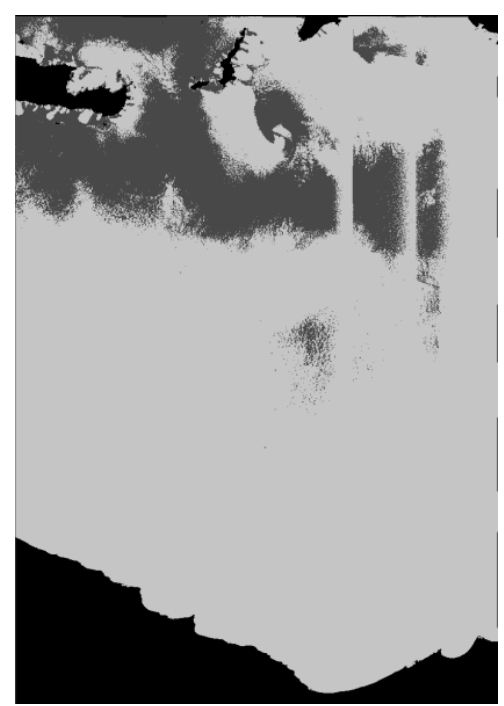

(c)

Figure 3. Example of ASAR image: (a) Original image before normalization; (b) Result after normalization and (c) Comparison mask with low wind areas.

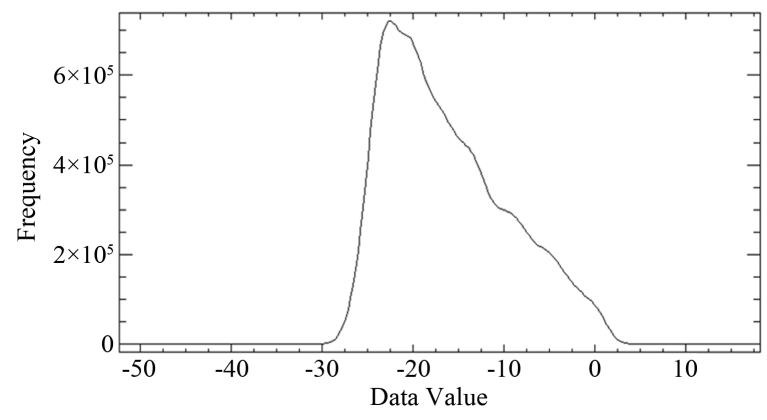

(a)

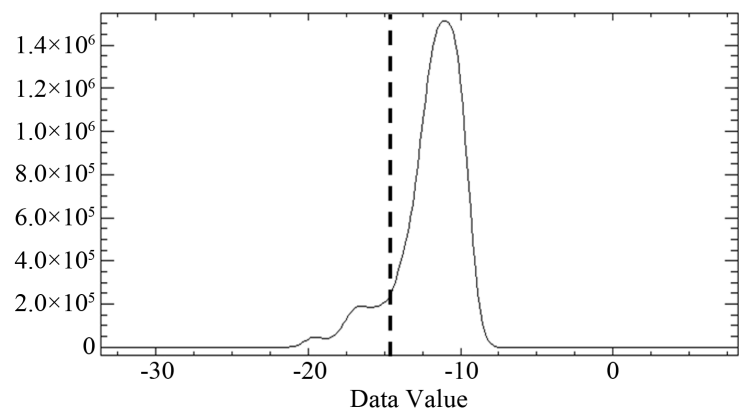

(b)

Figure 4. Histogram of (a) original image and (b) normalized image. Dashed line indicates the global threshold in the normalized image.

conditions were present in the images varying from $0 \mathrm{~m} / \mathrm{sec}$ to $12 \mathrm{~m} / \mathrm{sec}$, illustrating the exceptional oceanographic dynamics in the Aegean Sea. Wind speed was calculated using the CMOD5 model [21]. In order to examine the produced results two basic statistical values were calculated based on the error matrix of each image: the overall accuracy and the Kappa Index of Agreement (KIA). Overall accuracy represents the agreement of the corrected classified areas for each image for the two class problem (dark areas and background), while KIA is used to summarize the results of accuracy assessment between different error matrices i.e. to determine if one error matrix is significantly better than another. KIA is measured in a scale $0-1$ (Congalton and Green, 2008); KIA values greater than 0.8 represent strong agreement; values between 0.4 and 0.8 moderate agreement; and values below 0.4 represent poor agreement.

Accuracy assessment mask was created for each image and compared with the classification result. From the comparison accuracy matrixes created. For the A methodological procedure, which represent images without normalization, three thresholds were used i.e. GT, LT1 and LT2. From those the local threshold 2 (LT2) produced at least $11 \%$ higher accuracy results (overall accuracy) in all examined images. Therefore, LT2 was chosen to be compared with results from images after normalization (methodological procedure B). Their comparison showed incredible stability in terms of accuracy detection. In all images dark detection was superior after normalization against the LT2. Overall accuracies and KIA values for the examined dataset is given in Table 1. Overall accuracy is very high for both procedures. LT2 produced an overall accuracy of $65 \%-97 \%$ while normalized images presented $87 \%$ - 99\%. On the contrary, difference on the KIA measurement is significant be- 
tween the two procedures. LT2 resulted in poor agreement with KIA values from 0.06 to 0.41 while normalized images to very strong agreement with values from 0.87 to 0.95 . The latter could be explained by the confusion matrix itself. Overall accuracy represents the agreement of the two examined classes ("dark areas" and "clean background") between the accuracy assessment masks and the classified images (thresholds). The class size "dark areas" is limited against the large size of the class "clean background" and overall accuracy is biased by the agreement of the class "clean background". Unlike, KIA index takes into account the size differences of the two classes and reports the accuracy against a random classification. This explanation is confirmed with a close look at Table 2 i.e. example of confusion matrix for the example image of Figure 5. The normalized image has an overall accuracy of 0.98 against the 0.85 of the non normalized image (original). However, KIA is 0.92 and 0.35 for the normalized and the original image, respectively. The high overall accuracy of the non-normalized image is a result of the high accuracy of the class "clean background" since it contains the majority of the testing samples. However, this is not the case with KIA index where the sample size is taken into account.

Figure 5 and Figure 6 illustrate the detection capabilities of the examined methods. In Figure 5 dark areas were satisfactorily detected after normalization using the global threshold (case b). In contrast, global threshold did not have proper results in images without normalization (case c). Images were segmented in smaller areas (case d) for applying the two local thresholds (cases e and f). Both of them cannot detect dark areas in a proper way and several non-dark areas are included in the results. The efficiency of the normalization procedure is shown in Figure 6 where the global threshold detects ideally the dark areas after normalizing the SAR image. In parallel, the very strong backscatter signal in near range (illustrated with very bright pixels) was altered according to the signal in the middle range of the SAR image making it sufficiently better for visual interpretation.

\section{Conclusions}

The use of normalization in ASAR Wide Swath Imagery was examined for dark area detection in a GEOBIA environment. Normalization is referred to the correction of the progressive decrease of backscatter energy from

Table 1. Overall accuracies for the examined dataset in terms of overall accuracy and Kappa Index of Agreement.

\begin{tabular}{ccccccccccccc}
\hline & \multicolumn{10}{c}{ Image numbers } \\
\cline { 2 - 5 } & 1 & 2 & 3 & 4 & 5 & 6 & 7 & 8 & 9 & 10 \\
\hline Local threshold 2 overall accuracy & 0.96 & 0.97 & 0.85 & 0.76 & 0.87 & 0.89 & 0.65 & 0.89 & 0.92 & 0.91 \\
Local threshold 2 KIA & 0.06 & 0.5 & 0.35 & 0.25 & 0.11 & 0.29 & 0.12 & 0.15 & 0.31 & 0.41 \\
Normalized overall accuracy & 0.99 & 0.99 & 0.97 & 0.87 & 0.96 & 0.98 & 0.91 & 0.92 & 0.94 & 0.99 \\
Normalized KIA & 0.93 & 0.85 & 0.92 & 0.94 & 0.92 & 0.87 & 0.89 & 0.94 & 0.93 & 0.95 \\
\hline
\end{tabular}

Table 2. Comparison matrix with number of pixel matching for the normalized image (global threshold) and the original Image (local threshold 2).

\begin{tabular}{ccccccc}
\hline \multirow{2}{*}{$\begin{array}{c}\text { User/reference } \\
\text { class }\end{array}$} & \multicolumn{2}{c}{ Normalized image (global threshold) } & \multicolumn{3}{c}{ Original (local threshold 2) } \\
\cline { 2 - 7 } & Dark area & Background & Sum & Dark area & Background & Sum \\
\hline Dark area & $5,603,494$ & 0 & $5,603,494$ & $2,206,305$ & $1,555,796$ & $3,762,101$ \\
Background & 833,656 & $31,688,164$ & $32,521,820$ & $4,230,845$ & $30,132,368$ & $34,363,213$ \\
Sum & $6,437,150$ & $31,688,164$ & & $6,437,150$ & $31,688,164$ & \\
Producer acc. & 0.87 & 1 & 0.34 & 0.95 & \\
User acc. & 1 & 0.97 & & 0.58 & 0.87 & \\
KIA Per Class & 0.84 & 1 & 0.27 & 0.50 & \\
Overall Accuracy & 0.98 & & 0.85 & & \\
KIA & 0.92 & & & 0.35 & & \\
\hline
\end{tabular}




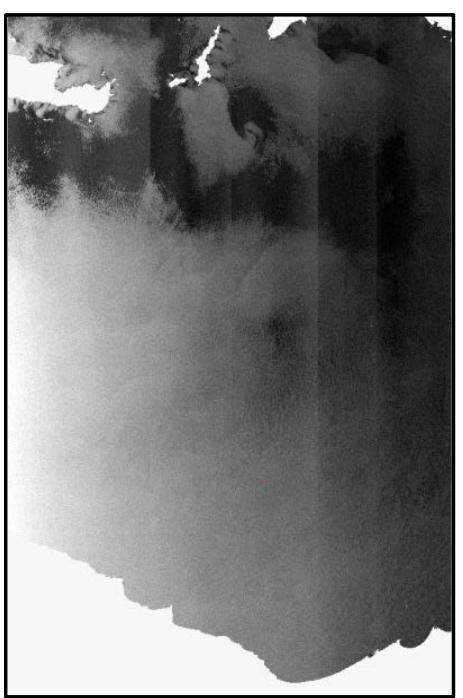

(a)

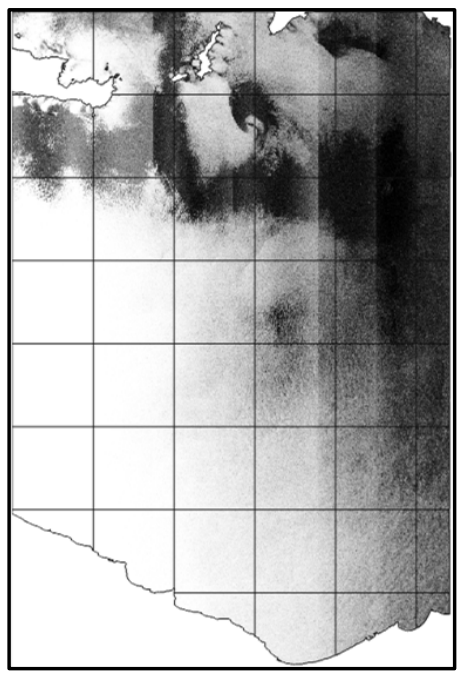

(d)

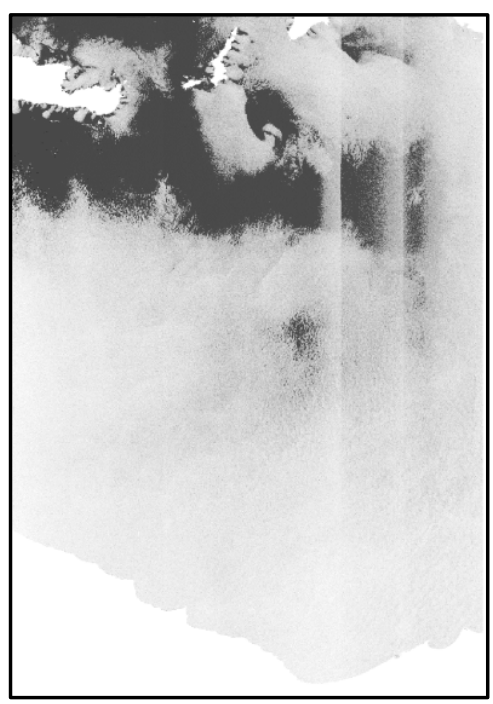

(b)

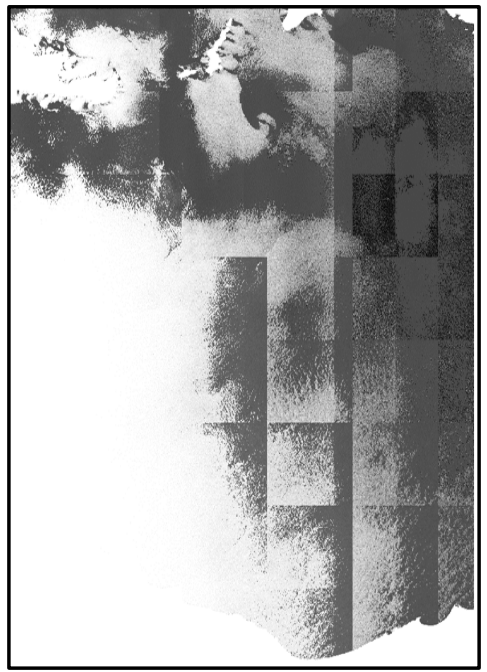

(e)

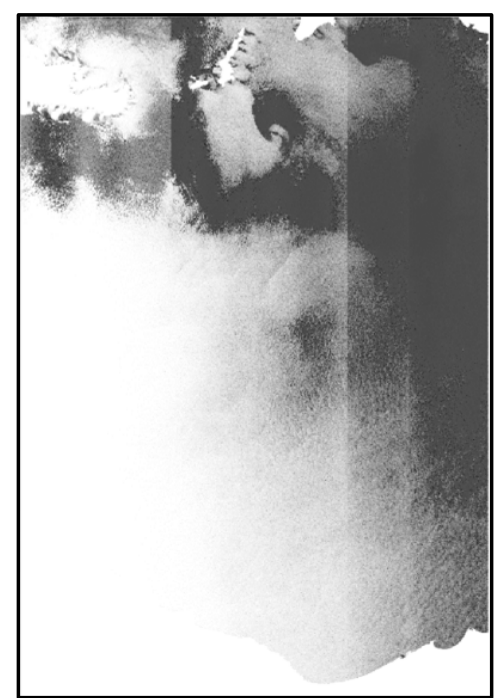

(c)

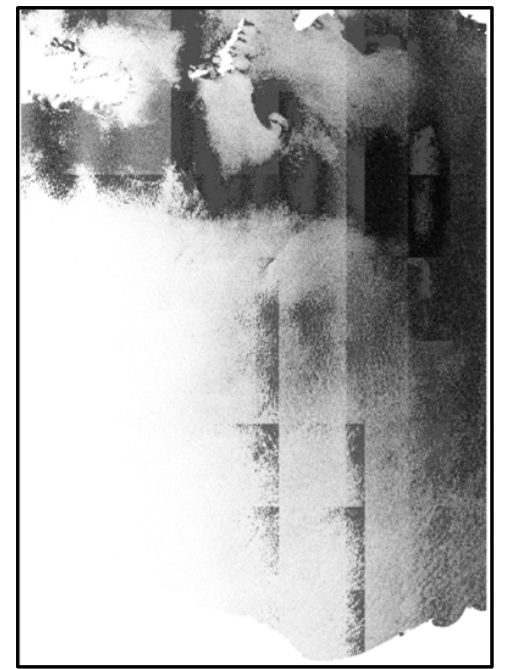

(f)

Figure 5. Example of the results of the dark area detection: (a) original image; (b) detection in the normalized image; (c) detection in original image by global threshold; (d) sub areas for local thresholds calculation; (e) detection in original image by local threshold 1; (f) detection in original image by local threshold 2.

near to far range in wide swath SAR images. Comparison was carried out on 10 images prior and afterwards normalization using comparison masks and confusion matrices. One global and two local thresholds were used in order to examine the stability of dark detection prior to normalization and only a global threshold after image normalization. With normalization inter comparison of SAR images is available regardless the sea state condition of the acquired area.

The results showed increased stability for the dark detection after normalization. The Kappa index was remarkable for the 10 examined images. In conclusion, normalization increased the ability to detect dark areas. Therefore, it can be used as a pre-processing step in image classification. On the contrary, local thresholds were insufficient in producing acceptable Kappa indexes when they were applied in the original image. Additionally, normalization can be used for manual image inspection without any additional need of image processing i.e. local image brightness manipulation. This procedure is important for operational procedures like low wind area detection or oil spill detection. Finally, normalization produces images with relative stable NRCS values, which can be used for classifying not only the dark formations but also the rest of sea areas. In case of object base processing these values can be used for creating the necessary object prior to any classification scheme. 


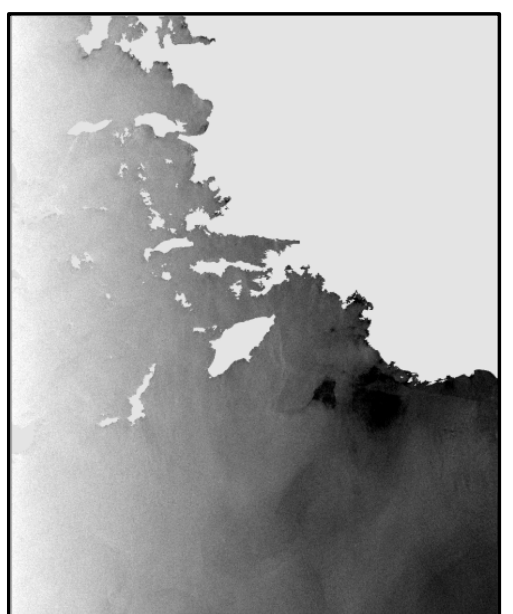

(a)

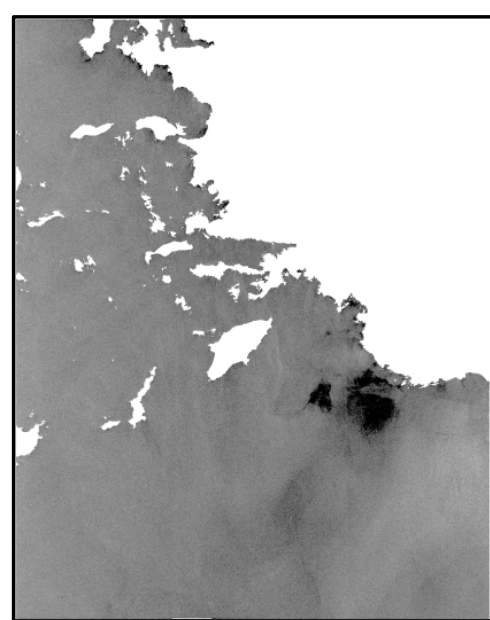

(b)

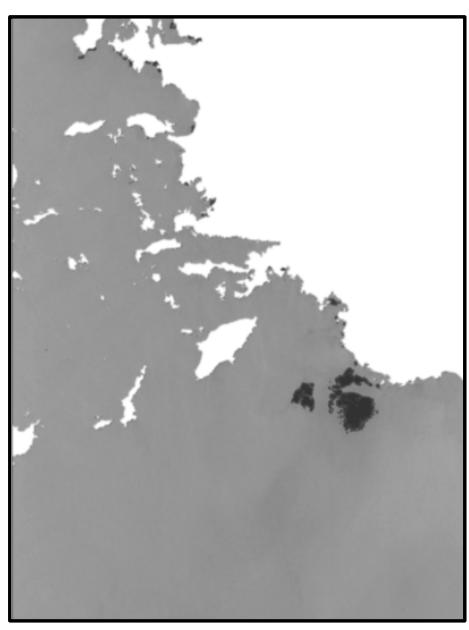

(c)

Figure 6. Example of the best performing result for dark area detection: (a) Original image; (b) Normalized image; (c) Dark area detection by global threshold.

\section{Acknowledgements}

This work is a part of the research project entitled "Automatic detection and classification of meso-scale ocean phenomena on satellite Advanced Synthetic Aperture Radar (ASAR) data" and has been implemented within the framework of the Action "Supporting Postdoctoral Researchers" of the Operational Program "Education and Lifelong Learning” (Action’s Beneficiary: General Secretariat for Research and Technology). It is co-financed by the European Social Fund (ESF) and the Greek State. The authors would also like to thank the European Space Agency (ESA) which provided the ENVISAT ASAR data for the study within their PI program.

\section{References}

[1] Fiscella, B., Giancaspro, A., Nirchio, F., Pavese, P. and Trivero, P. (2000) Oil Spill Detection Using Marine SAR Images. International Journal of Remote Sensing, 21, 3561-3566. http://dx.doi.org/10.1080/014311600750037589

[2] Nirchio, F., Sorgente, M., Giancaspro, A., Biamino, W., Parisato, E., Ravera, R., et al. (2005) Automatic Detection of Oil Spills from SAR Images. International Journal of Remote Sensing, 26, 1157-1174. http://dx.doi.org/10.1080/01431160512331326558

[3] Solberg, A., Brekke, C. and Husoy, P.O. (2007) Oil Spill Detection in Radarsat and Envisat SAR Images. IEEE Transactions on Geoscience and Remote Sensing, 45, 746-755. http://dx.doi.org/10.1109/TGRS.2006.887019

[4] Karathanassi, V., Topouzelis, K., Pavlakis, P. and Rokos, D. (2006) An Object-Oriented Methodology to Detect Oil Spills. International Journal of Remote Sensing, 27, 5235-5251. http://dx.doi.org/10.1080/01431160600693575

[5] Del Frate, F., Petrocchi, A., Lichtenegger, J. and Calabresi, G. (2000) Neural Networks for Oil Spill Detection Using ERS-SAR Data. IEEE Transactions on Geoscience and Remote Sensing, 38, 2282-2287. http://dx.doi.org/10.1109/36.868885

[6] Liu, A.K., Peng, C.Y. and Chang, S.Y.-S. (1997) Wavelet Analysis of Satellite Images for Coastal Watch. IEEE Journal of Oceanic Engineering, 22, 9-17. http://dx.doi.org/10.1109/48.557535

[7] Derrode, S. and Mercier, G. (2007) Unsupervised Multiscale Oil Slick Segmentation from SAR Images Using a Vector HMC Model. Pattern Recognition, 40, 1135-1147. http://dx.doi.org/10.1016/j.patcog.2006.04.032

[8] Benelli, G. and Garzelli, A. (1999) Oil-Spills Detection in SAR Images by Fractal Dimension Estimation. IEEE 1999 International Geoscience and Remote Sensing Symposium, IGARSS'99 (Cat. No.99CH36293), 1, 218-220. http://dx.doi.org/10.1109/IGARSS.1999.773452

[9] Marghany, M. (2001) RADARSAT Automatic Algorithms for Detecting Coastal Oil Spill Pollution. International Journal of Applied Earth Observation and Geoinformation, 3, 191-196. http://dx.doi.org/10.1016/S0303-2434(01)85011-X

[10] Topouzelis, K.N. (2008) Oil Spill Detection by SAR Images: Dark Formation Detection, Feature Extraction and Classification Algorithms. Sensors, 8, 6642-6659. http://dx.doi.org/10.3390/s8106642 
[11] Singha, S., Vespe, M. and Trieschmann, O. (2013) Automatic Synthetic Aperture Radar Based Oil Spill Detection and Performance Estimation via a Semi-Automatic Operational Service Benchmark. Marine Pollution Bulletin, 73, 199209. http://dx.doi.org/10.1016/j.marpolbul.2013.05.022

[12] Olson, D.B., Kourafalou, V.H., Johns, W.E., Samuels, G. and Veneziani, M. (2007) Aegean Surface Circulation from a Satellite-Tracked Drifter Array. Journal of Physical Oceanography, 37, 1898-1917. http://dx.doi.org/10.1175/JPO3028.1

[13] Nittis, K. and Perivoliotis, L. (2002) Circulation and Hydrological Characteristics of the North Aegean Sea: A Contribution from Real-Time Buoy Measurements. Mediterranean Marine Science, 3, 21-32. http://dx.doi.org/10.12681/mms.255

[14] Brekke, C. and Solberg, A. (2005) Oil Spill Detection by Satellite Remote Sensing. Remote Sensing of Environment, 95, 1-13. http://dx.doi.org/10.1016/j.rse.2004.11.015

[15] Desnos, Y.-L., Laur, H., Closa, J. and Meisl, P. (2000) The Envisat ASAR Processor and Data Products, SAR Work. Committee on Earth Observation Satellites (CEOS) Working Group on Calibration and Validation, 450.

[16] Rosich, B. and Meadows, P. (2004) Absolute Calibration of ASAR Level 1 Products, 26.

[17] Ulaby, F.T., Moore, R.K. and Fung, A.K. (1982) Microwave Remote Sensing: Active and Passive Volume II: Radar Remote Sensing and Surface Scattering and Emission Theory. Artech House.

[18] Wessel, P. and Smith, W.H.F. (1996) A Global, Self-Consistent, Hierarchical, High-Resolution Shoreline Database. Journal of Geophysical Research, 101, 8741-8743. http://dx.doi.org/10.1029/96JB00104

[19] Feindt, F., Wismann, V., Alpers, W. and Keller, W.C. (1986) Airborne Measurements of the Ocean Radar Cross Section at 5.3 GHz as a Function of Wind Speed. Radio Science, 21, 845-856. http://dx.doi.org/10.1029/RS021i005p00845

[20] Congalton, R. and Green, K. (2008) Assessing the Accuracy of Remotely Sensed Data: Principles and Practices. Second Edition, CRC Press, Boca Raton.

[21] Hersbach, H., Stoffelen, A. and De Haan, S. (2003) CMOD5: An Improved Geophysical Model Function for ERS C-Band Scatterometry. ECMWF Technical Memorandum No. 395, 1-52. 
Scientific Research Publishing (SCIRP) is one of the largest Open Access journal publishers. It is currently publishing more than 200 open access, online, peer-reviewed journals covering a wide range of academic disciplines. SCIRP serves the worldwide academic communities and contributes to the progress and application of science with its publication.

Other selected journals from SCIRP are listed as below. Submit your manuscript to us via either submit@scirp.org or Online Submission Portal.
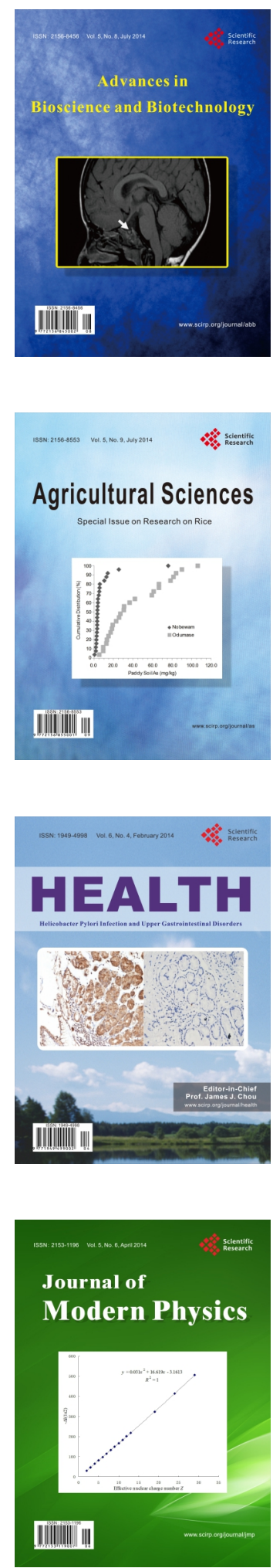
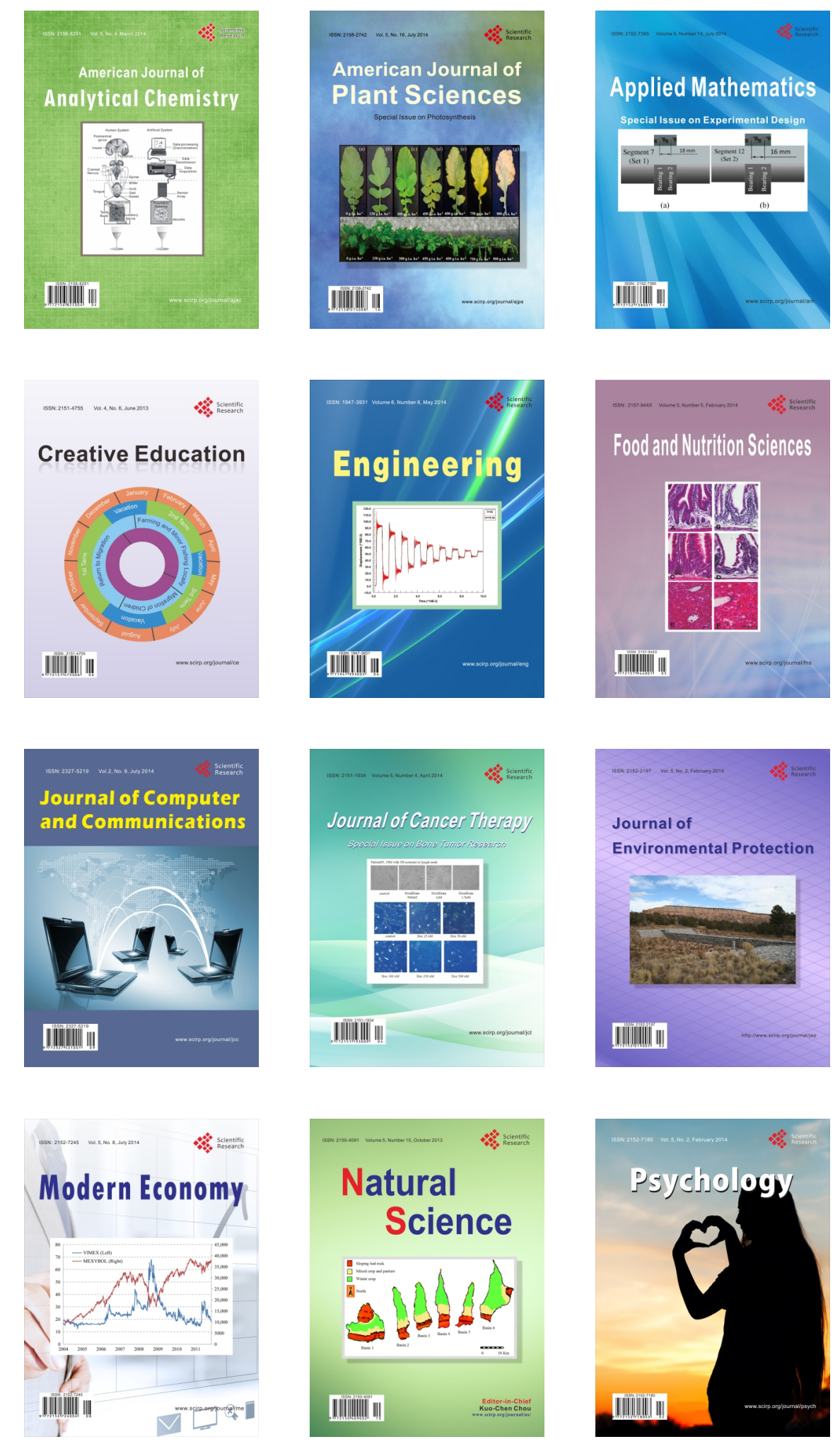